\title{
Polaromonas vacuolata gen. nov., sp. nov., a Psychrophilic, Marine, Gas Vacuolate Bacterium from Antarctica
}

\author{
R. L. IRGENS, J. J. GOSINK, AND J. T. STALEY* \\ Department of Microbiology (357242), University of Washington, Seattle, Washington 98195
}

\begin{abstract}
Several strains of a novel heterotrophic gas vacuolate bacterium were isolated from antarctic marine waters. The results of phylogenetic analyses in which $16 \mathrm{~S}$ ribosomal DNA sequencing was used, coupled with phenotypic tests, indicated that strain 34-P $\mathrm{P}^{\mathrm{T}}(\mathrm{T}=$ type strain) belongs to a new genus and species of the beta subgroup of the Proteobacteria, for which the name Polaromonas vacuolata is proposed. Although the other four strains studied probably belong to this new species, DNA-DNA hybridization tests were not conducted. The closest phylogenetic relatives of $\boldsymbol{P}$. vacuolata are the photosynthetic nonsulfur purple bacterium $R$ hodoferax fermentans and the hydrogen autotroph Variovorax paradoxus.
\end{abstract}

Although gas vacuolate heterotrophic bacteria are wellknown inhabitants of aquatic ecosystems, until recently none of these organisms had been observed in or isolated from marine habitats. In 1989 several types of gas vacuolate bacteria were found in Antarctica growing in association with the sea ice microbial community $(9,13)$. Sequencing and analyses of $16 \mathrm{~S}$ ribosomal DNAs (rDNAs) of a variety of these Antarctic gas vacuolate bacteria revealed that they were members of the Proteobacteria and the Flavobacterium-Cytophaga-Bacteroides phylogenetic groups (6). Within the Proteobacteria, the alpha, beta, and gamma subgroups were represented.

In this paper gas vacuolate members of the beta subgroup of the Proteobacteria that were isolated from the Palmer Peninsula area in Antarctica are described. Evidence that indicates that this group of strains comprises a new bacterial genus and species, Polaromonas vacuolata, is presented.

All strains were isolated from Antarctic waters off the Palmer Peninsula near the U.S. Palmer Station, Anvers Island, Antarctica. Several strains, including $34-\mathrm{P}^{\mathrm{T}}(\mathrm{T}=$ type strain), 41-P, 54-P, J-A, and J-B, were isolated from samples collected beneath sea ice (9). The presence of gas vesicles was confirmed by phase-contrast microscopy (Fig. 1) and by transmission electron microscopy (Fig. 2). The strains were grown and characterized as described previously (9), with the addition of tests for assessing generation time and urease activity (5). Resistance to various antibiotics was tested by placing a paper disk containing an antibiotic onto an SWC-m agar plate onto which the test strain had been spread. The plates were incubated at $4^{\circ} \mathrm{C}$, and susceptibility was determined by the presence of a zone of clearing that was more than $40 \mathrm{~mm}$ wide. The fatty acid compositions of all of the strains and the $16 \mathrm{~S}$ rDNA nucleotide sequence of strain $34-\mathrm{P}^{\mathrm{T}}$ were also determined as described previously (6).

Our 16S rDNA sequence was compared with the sequence determined independently in the laboratory of C. R. Woese (17). The $16 \mathrm{~S}$ rDNA sequence of $34-\mathrm{P}^{\mathrm{T}}$ was aligned with the most similar sequences in Ribosomal Database Project (RDP) release 5.0 by using the ALIGN_SEQUENCE program (10) and by manually comparing the structure with secondary structures provided by the RDP (7). Prealigned $16 \mathrm{~S}$ rRNA sequences for the following organisms were also obtained from the RDP (GenBank accession numbers are given in parentheses): Thiobacillus perometabolis ATCC 23370 (M79421 to M79423), Sphaerotilus natans (Z18534), Rubrivivax gelatinosus

\footnotetext{
${ }^{*}$ Corresponding author.
}

ATCC $17011^{\mathrm{T}}$ (D16213), Brachymonas denitrificans JCM 9216 ${ }^{\mathrm{T}}$ (D14320), Comamonas testosteroni ATCC $11996^{\mathrm{T}}$ (M11224), Stripa-derived bacterium (L20811), Variovorax paradoxus IAM 12373 ${ }^{\mathrm{T}}$ (D30793), str. PAD44 (D26231), Rhodoferax fermentans JCM $7819^{\mathrm{T}}$ (D16211), Alcaligenes faecalis ATCC $8750^{\mathrm{T}}$ (M22508), and Bordetella parapertussis ATCC $15311^{\mathrm{T}}$ (U04949). Finally, a BLAST search was also performed with the 1 October 1995 release of GenBank to determine if there were any sequences that were closely related to the sequence of $34-\mathrm{P}^{\mathrm{T}}$ but were not included in RDP release 5.0. Phylogenetic trees were generated by using PAUP, version $3.0 \mathrm{~s}$ (14), for parsimony analysis, DNADIST and NEIGHBOR (4) for distance analysis, and fastDNAml $(3,12)$ for likelihood analysis. MacClade, version 3.05 (11), was used to determine transition and transversion frequencies.

The results of phenotypic tests for growth, carbon source utilization, and various physiological features, as well as $\mathrm{G}+\mathrm{C}$ contents, have been reported previously (9); in addition, the following characteristics were also determined. The bacteria which were studied were short, unicellular, gram-negative rods $(0.8$ by 2 to $3 \mu \mathrm{m})$ that typically produced gas vacuoles which appeared as bright refractile areas within the cells (Fig. 1). Although the cells were nonmotile under usual culture conditions, they produced polar flagella in addition to gas vacuoles (Fig. 2). These bacteria produced circular, convex colonies with smooth, glistening surfaces and entire edges on agar plates. The colonies were chalky white in pigmentation. No growth occurred on SWC plates containing glucose $(0.1 \%)$ or L-arginine $(0.1 \%)$ as a carbon source when the plates were incubated in anaerobic jars (GasPak; BBL, Baltimore, Md.). The generation time, calculated from $A_{600}$ values at $4^{\circ} \mathrm{C}$, was $40 \mathrm{~h}$. Strain $34-\mathrm{P}^{\mathrm{T}}$ grew well at 0 to $12^{\circ} \mathrm{C}$. It did not grow at $15^{\circ} \mathrm{C}$. This strain grew when the initial $\mathrm{pH}$ of the medium was 6.0 to 9.5 . The $\mathrm{pH}$ of the spent medium was approximately 7.0 in all cases, except when sugars were present, in which case the $\mathrm{pH}$ was between 6.0 and 7.0. Good growth occurred in the presence of 0 to $6.0 \% \mathrm{NaCl}$. No growth occurred in the presence of $7.0 \% \mathrm{NaCl}$.

$P$. vacuolata $34-\mathrm{P}^{\mathrm{T}}$ was positive for urease and deaminase activities; susceptible to novobiocin $(30 \mu \mathrm{g})$, tetracycline (30 $\mu \mathrm{g})$, and neomycin $(30 \mu \mathrm{g})$; and resistant to streptomycin (10 $\mu \mathrm{g})$ and gentamicin $(10 \mu \mathrm{g})$.

Strain 34-P $\mathrm{P}^{\mathrm{T}}$ grew when the tryptone, yeast extract, beef extract, and vitamins of SWC-m were replaced with vitaminfree Casamino Acids (Difco Laboratories, Detroit, Mich.), indicating that vitamins are not required for growth. Good 


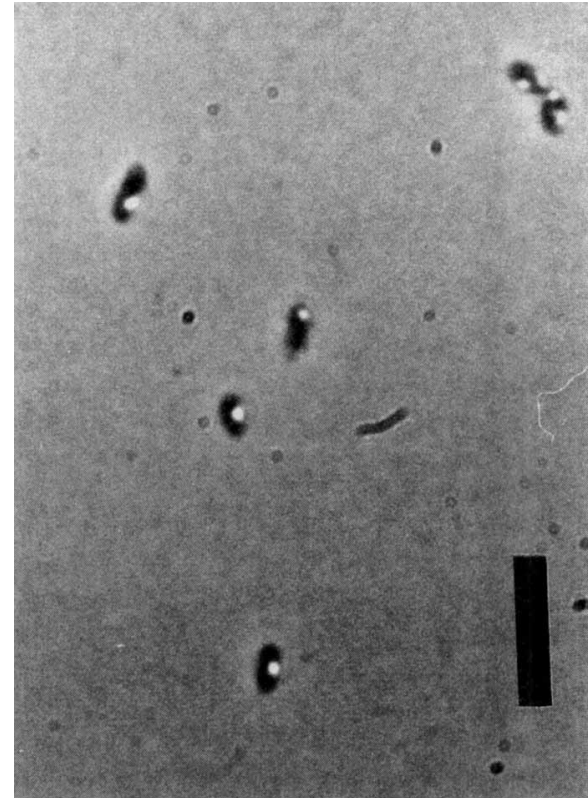

FIG. 1. Phase-contrast photomicrograph showing several cells of strain 34$\mathrm{P}^{\mathrm{T}}$. Note the bright, irregular gas vacuoles in the cells. Bar $=5 \mu \mathrm{m}$.

growth occurred in nutrient broth containing only $4.0 \mathrm{~g} / \mathrm{liter}$, but there was no growth in nutrient broth containing $8.0 \mathrm{~g} / \mathrm{liter}$.

In addition to the carbon sources indicated previously (9), the following carbon sources were utilized by strain $34-\mathrm{P}^{\mathrm{T}}$ : fumarate, citrate, succinate, 2-oxoglutarate, D-glucose, oxaloacetate, butyrate, DL-alanine, pyruvate, DL-glutamate, glycerol, DL-proline, propionate, DL-aspartate, DL-asparagine, acetate, and sorbitol.

The following carbon sources were not utilized: maltose,
D-fructose, xylose, D-ribose, L-fucose, formate, glycine, DL-serine, malonate, DL-isoleucine, DL-lysine, DL-histidine, DL-methionine, DL-valine, cellobiose, mannose, melibiose, melezitose, rhamnose, sorbose, trehalose, methanol, propanol, benzoate, erythritol, DL-threonine, and DL-tryptophan.

Whole-cell fatty acid analyses were performed on all strains. All strains contained large amounts of $16: 1 \omega 7 \mathrm{c}$ (74 to $79 \%$ ) and smaller amounts of 16:0 (14 to 17\%). In addition, a third fatty acid was present in smaller amounts ( 7 to $9 \%$ ). This fatty acid was identified as $18: 1 \omega 7 \mathrm{c}, 18: 1 \omega 9 \mathrm{t}$, or $18: 1 \omega 12 \mathrm{t}$ or possibly a combination of more than one of these compounds; its actual identity could not be determined by the procedure and instruments used. Such predominance of a single fatty acid is unusual in bacteria, and this is the highest level of $16: 1 \omega 7 \mathrm{c}$ that we are aware of in any bacterial species.

The $16 \mathrm{~S}$ rDNA sequence of strain $34-\mathrm{P}^{\mathrm{T}}$ was compared with the sequences of other bacteria included in the RDP database (Table 1). On the basis of simple sequence homology, the most closely related previously described organisms are Rhodoferax fermentans, a nonsulfur purple bacterium (8), and $V$. paradoxus, a chemoorganotroph and facultative lithoautotroph (1, 16). As determined by the same method, however, strain $34-P^{T}$ is most closely related to the environmental $16 \mathrm{~S}$ rDNA sequences str. Stripa and str. PAD44. The Stripa-derived 16S rDNA sequence was obtained from deep groundwater in the Stripa mine in Sweden (2). The str. PAD44 or env. PAD44 sequence is a sequence that was obtained from a paddy field (15). However, both of these sequences are environmental sequences without organisms available for comparison, and so it is impossible to determine how similar the actual organisms are to one another in other respects. In addition, these sequences are only partial $16 \mathrm{~S}$ rDNA sequences, and so the actual levels of relatedness might be different if the complete sequences were available.

A phylogenetic analysis of the sequences revealed that the relationship of the organisms was uncertain. A preliminary

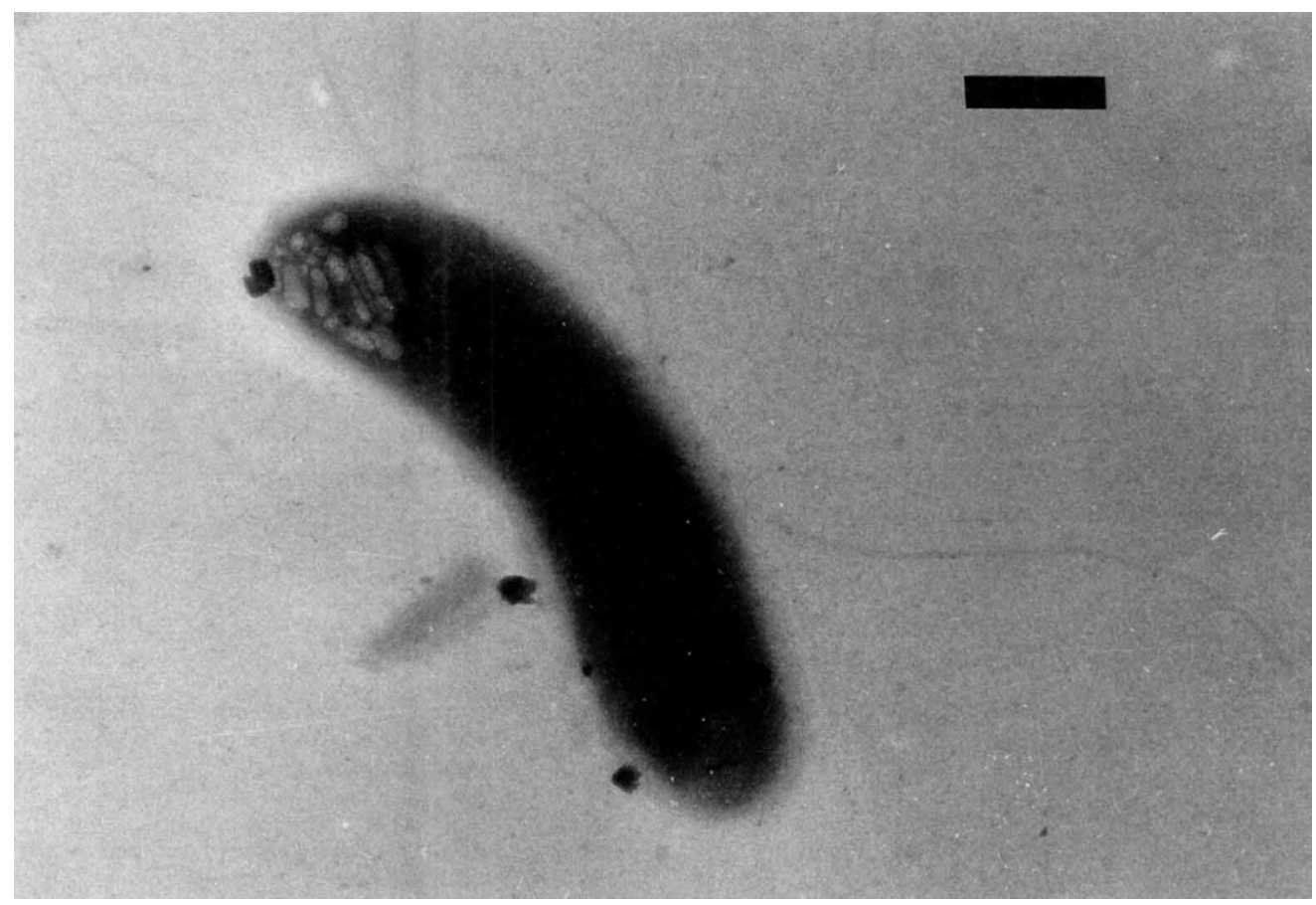

FIG. 2. Electron micrograph of $34-\mathrm{P}^{\mathrm{T}}$ showing a cell containing several gas vesicles. The flagella are not attached. Bar $=0.5 \mu \mathrm{m}$. 
TABLE 1. Levels of homology of the $P$. vacuolata $16 \mathrm{~S}$ rDNA sequence and the most closely related 16S rDNA sequences obtained from the RDP

\begin{tabular}{|c|c|c|c|c|c|c|c|c|c|c|c|c|}
\hline \multirow[b]{2}{*}{ Sequence } & \multicolumn{12}{|c|}{ Mean distance or no. of base differences ${ }^{a}$} \\
\hline & 竞 & 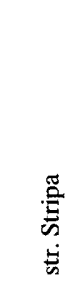 & 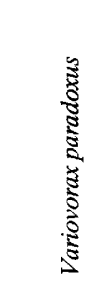 & 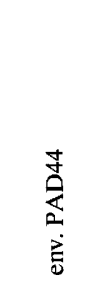 & 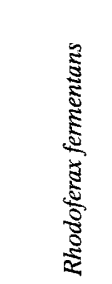 & 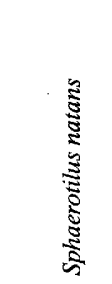 & 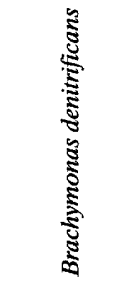 & 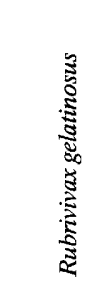 & 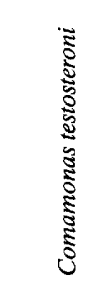 & 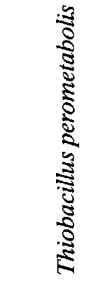 & 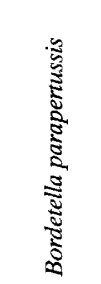 & 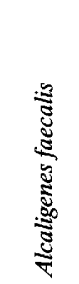 \\
\hline $34-P^{T}$ & & 0.05 & 0.052 & 0.059 & 0.065 & 0.074 & 0.083 & 0.084 & 0.085 & 0.113 & 0.121 & 0.124 \\
\hline str. Stripa & 44 & & 0.033 & 0.055 & 0.057 & 0.076 & 0.053 & 0.066 & 0.046 & 0.096 & 0.092 & 0.103 \\
\hline Variovorax paradoxus & 75 & 29 & & 0.03 & 0.042 & 0.078 & 0.08 & 0.079 & 0.066 & 0.11 & 0.116 & 0.12 \\
\hline env. PAD44 & 16 & 15 & 8 & & 0.03 & 0.067 & 0.037 & 0.074 & 0.037 & 0.097 & 0.071 & 0.078 \\
\hline Rhodoferax fermentans & 94 & 50 & 61 & 8 & & 0.087 & 0.079 & 0.088 & 0.08 & 0.113 & 0.115 & 0.117 \\
\hline Sphaerotilus natans & 100 & 66 & 105 & 18 & 117 & & 0.091 & 0.048 & 0.096 & 0.094 & 0.101 & 0.113 \\
\hline Brachymonas denitrificans & 120 & 46 & 116 & 10 & 114 & 122 & & 0.071 & 0.052 & 0.109 & 0.097 & 0.123 \\
\hline Rubrivivax gelatinosus & 122 & 57 & 114 & 20 & 128 & 65 & 103 & & 0.087 & 0.082 & 0.097 & 0.12 \\
\hline Comamonas testosteroni & 123 & 40 & 96 & 10 & 116 & 129 & 76 & 126 & & 0.112 & 0.115 & 0.127 \\
\hline Thiobacillus perometabolis & 97 & 56 & 94 & 23 & 97 & 80 & 93 & 70 & 96 & & 0.115 & 0.126 \\
\hline Bordetella parapertussis & 173 & 80 & 165 & 19 & 164 & 135 & 139 & 139 & 164 & 98 & & 0.058 \\
\hline Alcaligenes faecalis & 176 & 89 & 170 & 21 & 166 & 150 & 174 & 171 & 181 & 107 & 82 & \\
\hline
\end{tabular}

${ }^{a}$ The numbers on the upper right are the mean distances between sequence pairs adjusted for missing data, and the numbers on the lower left are total numbers of base differences for the pairs of sequences.

phylogenetic set of the four most parsimonious trees obtained with PAUP, version 3.0s (14), was analyzed by using MacClade, version $3.05(11)$, to produce a substitution matrix to correct for the different rates obtained for the 12 different types of nucleotide substitutions (e.g., $\mathrm{A} \rightarrow \mathrm{C}$ or $\mathrm{G} \rightarrow \mathrm{U}$, etc.) (data not shown). The overall rate of transitions to transversions was determined to be 1.3. A rescaled consistency index weighting mask was also constructed from these trees by using MacClade, version 3.05 (11).

The substitution matrix was reapplied to the aligned data set in PAUP, version 3.0s (14), and the most parsimonious trees were determined by using the branch and bound option with both the original data set and 100 bootstrap-resampled data sets. The original data set (with the applied substitution matrix) yielded four equally parsimonious trees whose length was 638. These trees differed in the relationships among env. PAD44, Rhodoferax fermentans, $V$. paradoxus, str. Stripa, and strain 34- $\mathrm{P}^{\mathrm{T}}$. The consistency index for these trees was 0.386 . The bootstrap values only weakly supported any particular branching structure near 34- $\mathrm{P}^{\mathrm{T}}$ (Fig. 3). Three similar trees were obtained when corrections for the substitution matrix and the rescaled consistency index weighting mask were used simultaneously (data not shown).

The aligned data set used in the parsimony analysis was also resampled to make 100 bootstrap replicates by using SEQBOOT (4). Distance matrix tables for both the original data set and the bootstrap resampled data sets were constructed by using DNADIST (4) with a Kimura 2 parameter correction, a jumbled input order, and a transition-to-transversion ratio of 1.3. The original and bootstrap distance matrices were analyzed by NEIGHBOR (4). Again, the exact relationship between strain 34- $\mathrm{P}^{\mathrm{T}}$ and its nearest phylogenetic neighbors was not certain. This method identified $34-\mathrm{P}^{\mathrm{T}}$ as a sister taxon of a clade containing $V$. paradoxus and Rhodoferax fermentans and all three of these organisms as members of the sister clade closest to Brachymonas denitrificans and C. testosteroni. While there is clear bootstrap support (bootstrap value, $81 \%$ ) for placing 34- $\mathrm{P}^{\mathrm{T}}$ in this group of beta subgroup Proteobacteria, with Brachymonas denitrificans and $C$. testosteroni ${ }^{\mathrm{T}}$ as members of a sister clade (bootstrap value, 77\%), the level of support for an exclusive relationship to $V$. paradoxus and Rhodoferax fermentans is quite low (bootstrap value, 52\%).

Finally, the aligned data set and 100 bootstrap replicates were analyzed by using fastDNAml $(3,12)$, with the base frequencies determined empirically and the ratio of transition to transversion set at 1.3. Again, the more distantly related taxa showed a branching topology similar to that determined with

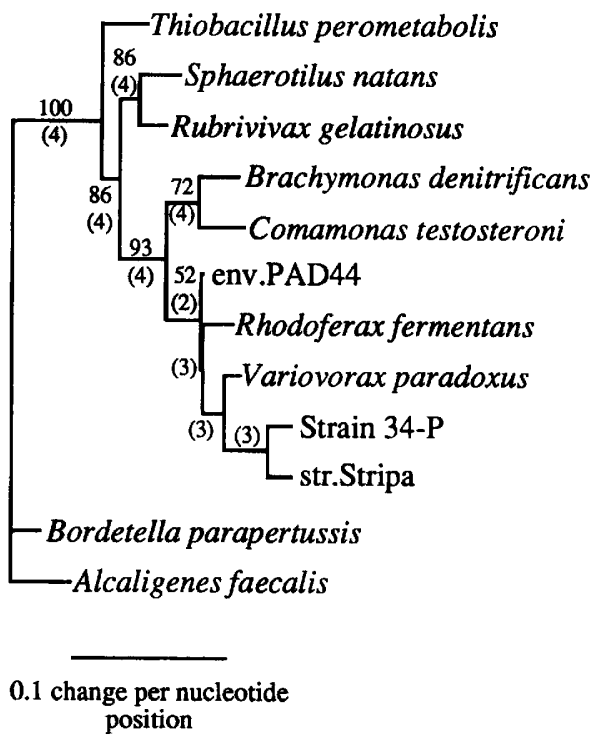

FIG. 3. Phylogenetic relatedness of $P$. vacuolata $34-\mathrm{P}^{\mathrm{T}}$ and the most closely related species. This maximum-parsimony tree was determined by an exact (branch-and-bound) search method, using a substitution matrix to correct for the various rates of nucleotide substitutions. This is one of four equally parsimonious trees. The numbers in parentheses near the branch points indicate how many of the four equally most parsimonious trees shared that branch structure. The numbers not in parentheses near the clades indicate the percentages of bootstrap support for the clades based on 100 bootstrap resamplings. Only bootstrap values of $50 \%$ or more are shown. 
TABLE 2. Phenotypic comparison of $P$. vacuolata and the two phylogenetically most closely related species ${ }^{a}$

\begin{tabular}{|c|c|c|c|c|c|c|c|c|}
\hline Organism & Cell shape & $\begin{array}{c}\text { Gas } \\
\text { vesicles }\end{array}$ & $\begin{array}{l}\text { Photo- } \\
\text { synthesis }\end{array}$ & $\begin{array}{l}\text { Position of } \\
\text { flagella }\end{array}$ & $\begin{array}{c}\mathrm{O}_{2} \\
\text { requirement }\end{array}$ & $\begin{array}{l}\text { Temperature } \\
\text { relationship }\end{array}$ & $\begin{array}{c}\text { Colony } \\
\text { pigmentation }\end{array}$ & $\begin{array}{l}\mathrm{G}+\mathrm{C} \text { content } \\
(\mathrm{mol} \%)\end{array}$ \\
\hline Polaromonas vacuolata & Rods & + & - & Polar & Obligate aerobe & Psychrophilic & White & $52-57$ \\
\hline Rhodoferax fermentans & Curved rods & - & + & Polar & Facultative aerobe & Mesophilic & Peach-brown & \\
\hline Variovorax paradoxus & $\begin{array}{l}\text { Curved or } \\
\text { straight rods }\end{array}$ & - & - & Peritrichous & Obligate aerobe & Mesophilic & Yellow & $67-69$ \\
\hline
\end{tabular}

${ }^{a}$ Data are from references 1,8 , and 9 .

the parsimony and distance trees. As in the neighbor-joining analysis, strain $34-\mathrm{P}^{\mathrm{T}}$ was between the Stripa mine clone and a clade containing Rhodoferax fermentans and $V$. paradoxus. This is in contrast to the results of the parsimony analysis, in which strain 34- $\mathrm{P}^{\mathrm{T}}$ was identified (with weak support) as a sister taxon of the Stripa mine clone. Also, like the parsimony and distance methods, the maximum-likelihood bootstrap analysis produced no significant support for any particular branching order near strain $34-\mathrm{P}^{\mathrm{T}}$ and only $59 \%$ support for a clade that included only strain $34-\mathrm{P}^{\mathrm{T}}, V$. paradoxus, Rhodoferax fermentans, env. PAD44, and str. Stripa.

Each of these methods produced slightly different trees. From all of the trees, however, it is clear that strain $34-\mathrm{P}^{\mathrm{T}}$ is most closely related to Rhodoferax fermentans, $V$. paradoxus, str. Stripa, and env. PAD44. On the other hand, strain 34- $\mathrm{P}^{\mathrm{T}}$ is not photosynthetic and does not grow as a nonsulfur purple bacterium under conditions used for the growth of Rhodoferax fermentans. Also, strain 34- $\mathrm{P}^{\mathrm{T}}$ differs by 5 and $7 \%$ in $16 \mathrm{~S}$ rDNA base homology from $V$. paradoxus and Rhodoferax fermentans, respectively. Furthermore, other genotypic and phenotypic data indicate that $P$. vacuolata, $V$. paradoxus, and Rhodoferax fermentans differ markedly (Table 2); for example, the $\mathrm{G}+\mathrm{C}$ contents of these organisms are 52 to 57,67 to 69 , and 60 mol\%, respectively. In addition, $V$. paradoxus and Rhodoferax fermentans are pigmented, are not gas vacuolate, and differ from $P$. vacuolata in cell shape and motility (Table 2).

This appears to be the first report of a gas vacuolate member of the beta subgroup of the Proteobacteria. This is not surprising, however, because some members of both the alpha and gamma subgroups of the Proteobacteria are known to be gas vacuolate. A logical conclusion is that this feature is widespread among this phylogenetic group, many members of which are found in aquatic habitats, where gas vacuolate bacteria most commonly reside.

On the basis of its phenotypic features and the results of an analysis of its levels of 16S rDNA base homology, as discussed above, 34- $\mathrm{P}^{\mathrm{T}}$ is sufficiently different from other bacteria to warrant creation of a new genus. We therefore propose that the new genus Polaromonas should be described as follows.

Description of Polaromonas gen. nov. Polaromonas (Po.lar .o.mo'nas. M. L. adj. polaris, pertaining to the geographic poles; Gr. fem. n. monas, unit; M. L. fem. n. Polaromonas, polar bacterium). Cigar-shaped, gram negative rods that are 0.8 by 2.0 to $3.0 \mu \mathrm{m}$. Encapsulated. Aerobic. Chemoorganotrophic and catalase and oxidase positive. Requires amino acids, but not vitamins, for growth. Motile by means of a polar flagellum. Cells may contain gas vesicles. Psychrophilic. The maximum growth temperature of known strains is $15^{\circ} \mathrm{C}$.

The $\mathrm{G}+\mathrm{C}$ contents are 52 to $57 \mathrm{~mol} \%$ (as determined by the thermal denaturation method) (9).

The only species is the type species, Polaromonas vacuolata.

Description of Polaromonas vacuolata sp. nov. Polaromonas vacuolata (va.cu.o.la'ta. L. adj. vacuus, empty; N. L. part. adj. vacuolata, equipped with gas vacuoles). Cells contain gas ves- icles. The optimum temperature for growth is $4^{\circ} \mathrm{C}$, and the growth temperature range is 0 to $12^{\circ} \mathrm{C}$. Colonies are snowy white, circular, and convex with smooth surfaces and entire edges. The more gas vesicles within the cells, the whiter the colony. Good growth occurs in media containing $\mathrm{NaCl}$ at concentrations ranging from 0 to $6.0 \%$, but no growth occurs in the presence of $7.0 \% \mathrm{NaCl}$.

Tests for catalase, oxidase, urease, deaminase, and lipase are positive. Amylase, protease (gelatin), tryptophanase (indole), nitrate reductase, cysteine desulfurase, and agarase tests are negative.

The following carbon sources are utilized: acetate, lactate, malate, fumarate, pyruvate, propionate, citrate, succinate, oxaloacetate, butyrate, 2-oxoglutarate, glucose, glycerol, sorbitol, DL-alanine, DL-glutamate, DL-proline, DL-aspartate, and DL-asparagine.

The following carbon sources are not utilized: maltose, Dfructose, sucrose, lactose, D-xylose, D-ribose, formate, cellobiose, D-mannose, L-fucose, melibiose, melezitose, L-rhamnose, sorbose, trehalose, methanol, ethanol, erythritol, propanol, benzoate, malonate, DL-arginine, glycine, DL-serine, DL-isoleucine, DL-lysine, DL-histidine, DL-ornithine, DL-methionine, DLvaline, DL-threonine, and DL-tryptophan.

The fatty acid composition is $75 \% 16: 1 \omega 7 \mathrm{c}, 17 \% 16: 0$, and $8 \% 18: 1 \omega 7 \mathrm{c}, 18: 1 \omega 9 \mathrm{t}$, or $18: 1 \omega 12 \mathrm{t}$.

Susceptible to novobiocin, tetracycline, neomycin, and kanamycin. Resistant to bacitracin, streptomycin, and gentamicin.

The $\mathrm{G}+\mathrm{C}$ content is $52.0 \mathrm{~mol} \%$ (as determined by the thermal denaturation method).

The type strain is $P$. vacuolata 34-P (= ATCC 51984).

It is likely that the other strains included in this study are members of the same species on the basis of the results of the phenotypic tests that were performed, including the whole-cell fatty acid analysis. However, DNA-DNA hybridization tests were not conducted, and so this has not been verified.

This work was supported in part by National Science Foundation grant BSR 90006788 to J.T.S. and by National Institute of General Medical Sciences National Research Service Award 2T32 GM07270-19 to J.J.G.

We appreciate the help of Russell P. Herwig and Nancy Pellerin with sample collection and thank James Gray for excellent technical assistance. We also acknowledge the assistance of Carl Woese, who independently confirmed the $16 \mathrm{~S}$ rDNA sequence of $34-\mathrm{P}^{\mathrm{T}}$.

\section{REFERENCES}

1. Davis, D. H., M. Doudoroff, and R. Y. Stanier. 1969. Proposal to reject the genus Hydrogenomanas: taxonomic implications. Int. J. Syst. Bacteriol. 19: 375-390.

2. Ekendahl, S., J. Arlinger, F. Ståhl, and K. Pedersen. 1994. Characterization of attached bacterial populations in deep granitic groundwater from the Stripa research mine by $16 \mathrm{~S}$ rRNA gene sequencing and scanning electron microscopy. Microbiology 140:1575-1583.

3. Felsenstein, J. 1981. Evolutionary trees from DNA sequences: a maximum 
likelihood approach. J. Mol. Evol. 17:368-376.

4. Felsenstein, J. 1989. PHYLIP-phylogeny inference package (version 3.2) Cladistics 5:164-166.

5. Gerhardt, P., R. G. E. Murray, R. N. Costilow, E. W. Nester, W. A. Wood, N. R. Krieg, and G. B. Phillips (ed.). 1981. Manual of methods for general bacteriology. American Society for Microbiology, Washington, D.C

6. Gosink, J. J., and J. T. Staley. 1995. Biodiversity of gas vacuolate bacteria from antarctic sea ice and water. Appl. Environ. Microbiol. 61:3486-3489.

7. Gutell, R. R. 1993 . Collection of small subunit (16S- and 16S-like) ribosomal RNA structures. Nucleic Acids Res. 21:3051-3054.

8. Hiraishi, A., Y. Hoshino, and T. Satoh. 1991. Rhodoferax fermentans gen. nov., sp. nov., a phototrophic purple nonsulfur bacterium previously referred to as "Rhodocyclus gelatinosus-like" group. Arch. Microbiol. 155:330-336.

9. Irgens, R. L., I. Suzuki, and J. T. Staley. 1989. Gas vacuolate bacteria obtained from marine waters of Antarctica. Curr. Microbiol. 18:261-265.

10. Larsen, N., G. J. Olsen, B. L. Maidak, M. J. McCaughey, R. Overbeek, T. J. Macke, T. L. Marsh, and C. R. Woese. 1993. The Ribosomal Database
Project. Nucleic Acids Res. 21:3021-3023.

11. Maddison, W. P., and D. R. Maddison. 1992. MacClade: analysis of phylogeny and character evolution. Version 3.0. Sinauer Associates, Sunderland, Mass.

12. Olsen, G. J., H. Hagstrom, and R. Overbeek. 1994. fastDNAml: a tool for construction of phylogenetic trees of DNA sequences using maximum likelihood. Comput. Appl. Biosci 10:41-48.

13. Staley, J. T., R. L. Irgens, and R. P. Herwig. 1989. Gas vacuolate bacteria from the sea ice of Antarctica. Appl. Environ. Microbiol. 55:1033-1036.

14. Swofford, D. L. 1991. PAUP: phylogenetic analysis using parsimony. Illinois Natural History Survey, Champaign.

15. Ueda, T. 1993. Unpublished data.

16. Willems, A., J. D. Ley, M. Gillis, and K. Kersters. 1991. Comamonadaceae, a new family encompassing the acidovorans rRNA complex, including Variovorax paradoxus gen. nov., comb. nov., for Alcaligenes paradoxus (Davis 1969). Int. J. Syst. Bacteriol. 41:445-450.

17. Woese, C. R. Personal communication. 